\title{
Configuration Lifecycle Management - Future of Product Configurators
}

\author{
Myrodia, Anna; Randrup, Thomas; Hvam, Lars
}

Published in:

Proceedings of the 2018 IEEE International Conference on Industrial Engineering and Engineering Management (IEEM)

Link to article, DOI:

10.1109/IEEM.2018.8607471

Publication date:

2018

Document Version

Peer reviewed version

Link back to DTU Orbit

Citation (APA):

Myrodia, A., Randrup, T., \& Hvam, L. (2018). Configuration Lifecycle Management - Future of Product Configurators. In Proceedings of the 2018 IEEE International Conference on Industrial Engineering and Engineering Management (IEEM) (pp. 1315-1319). IEEE. https://doi.org/10.1109/IEEM.2018.8607471

\section{General rights}

Copyright and moral rights for the publications made accessible in the public portal are retained by the authors and/or other copyright owners and it is a condition of accessing publications that users recognise and abide by the legal requirements associated with these rights.

- Users may download and print one copy of any publication from the public portal for the purpose of private study or research.

- You may not further distribute the material or use it for any profit-making activity or commercial gain

- You may freely distribute the URL identifying the publication in the public portal 


\title{
Configuration Lifecycle Management - Future of Product Configurators
}

\author{
A. Myrodia ${ }^{1,2}$, T. Randrup ${ }^{1}$, L. Hvam ${ }^{2}$ \\ ${ }^{1}$ Configit A/S, Copenhagen, Denmark \\ ${ }^{2}$ Department of Management Engineering, Technical University of Denmark, Kgs. Lynbgy, Denmark \\ (amyrodia@configit.com)
}

\begin{abstract}
The utilization of product configurators (PC) in the sales phase is a well-established solution for manufacturing companies of configurable products and it comes along with several benefits. However, there is a tendency identified currently in the industry that companies use PC to cover more lifecycle phases, such as engineering, manufacturing and service. This is described as configuration lifecycle management (CLM). Digitalization, increasing complexity and competitiveness are the main drivers of this need. This research analyses 59 case studies using $\mathrm{PC}$ in several lifecycle phases. The findings from the case studies confirm this tendency and the need towards a complete CLM solution is discussed.
\end{abstract}

Keywords - Configuration lifecycle management, product configuration, product lifecycle, case study

\section{INTRODUCTION}

In today's continuous evolving environment, manufacturing companies of configurable products have to overcome several challenges to maintain their competitive advantage. To keep up with the current industrial phenomena of digitalization, product personalization and global supply-chain networks, companies need to be agile and adapt to changes rapidly in a volatile environment [1]. There is a pressure for companies to go through this transformation smoothly and to ensure that all dimensions of the organization (products, processes, people, and technologies) adapt and enhance the new work routines [2].

In addition, the increased demand of highly customized and personalized products from customers, together with the advances in technology that allow for this high degree of individualization, have lead manufacturers to increase the number of product variant they offer to the market. This phenomenon has become more often in the recent years, leading to unavoidable increase of complexity. As product complexity increases due to proliferation, the complexity of handling product information increases as well [3]. In particular, when this product information comes from different sources and has to be shared across numerous users, the need of validating it becomes imperative [4].

Configuration lifecycle management (CLM) addresses these needs for manufacturing companies of configurable products [5]. CLM manages all product configuration data and describes product models in a universal manner, containing product information that can be used across different departments and in different lifecycle phases of configurable products [6].

Product configurators (PCs) are well-established solutions helping companies to address the need for digital transformation and complexity management. They do so by supporting process and product standardization, and validity and sharing of configuration data Manufacturers of configurable products are using sales configurators for their standard product offerings. Lately, it is observed that PCs are used to some extent for engineer-to-order products as well. The main reason for this extended use of PCs in relation to the products included in the system is due to the gains from its use.

Another parameter where extended use of PCs has been reported, is related to the product lifecycle phases. Data describing configurable products across all life cycle phases (engineering, sales, manufacturing, service) are included and handled by PCs [7]. So far, sales PCs have been used to guide the customer to select the most suitable product for his needs and to generate the quotation. This use of PCs is linked a number of benefits, which include among others, reduced sales cycle time, improved quality of quotations, improved pricing accuracy and increased customer satisfaction [8]. These PCs support the commercial process [9].

However, PCs can be used to support technical processes as well [9]. In regards to product's life cycle, PCs can be used to handle configuration data related to engineering, manufacturing and servicing. This extended use of PCs serves the need of the process continuity, seamless integrations and data sharing across all involved parties in an organization. The advances in configuration related technology and the improvement of the actual configuration tools that are offered to the market are also driving this extended use of PCs. Especially when it comes to sales configurators the market is considered mature enough. This is not only because of the number of different solutions, but also due to the higher number of experiences and lesson learnt from the implementation of sales configurators [10].

Therefore, this research focuses on examining this development of the use of PCs across all lifecycle phase of configurable products. As this is a need coming from the industry, the paper presents the findings from 59 case studies regarding the extension of PCs implementation to describe products across several lifecycle phases. Based on the results of the analysis, we argue that CLM describes the future of PCs in terms of utilization. 
The remainder of the paper is structured as follows. Section II presents the findings from the literature regarding the need of CLM. Section III describes the research methodology. Section IV presents the empirical evidence and the findings from the analysis. Finally, section $\mathrm{V}$ discusses the results in relation to the findings from the literature review and section VI provides some overall conclusions and pointers for future study.

\section{LITERATURE REVIEW}

The implementation of a PC in the sales phases has been discussed in detail in the literature. A significant amount of research papers focuses on the benefits from utilizing a PC, the structure of the PC and on the knowledge capture and product modeling techniques [11].

A main aspect widely discussed in relation to PCs is the process standardization. The need of process standardization is imperative to maintain agility, especially in large organizations operating globally and having international supply chains [12]. Process standardization is a requirement for a successful implementation of a PC.

In particular, in the sales phase due to the process standardization, companies are experiencing shorter lead times and shorter cycle times for the sales process, faster quotation process and improved communication of the sales personnel with the customers [8]. In a similar way, for the successful implementation of a PC in any of the other lifecycle phases, process standardization is a prerequisite.

In the engineering phase of a product's life cycle, product standardization is achieved through mass customization techniques and modular design [13,14]. In this way, product complexity can be controlled and reduced. By standardizing the product assortment, companies have a better overview of their product offerings and the hidden costs of external product variety.

Product standardization is another requirement when implementing a PC. Therefore, PCs are considered to be very efficient tools to support control and reduction of product complexity. Through the use of a PC manufacturers have a better control of their product portfolio, more accurate overview of the profitability of the products and a clearer picture of the market requirements [15].

Changes in the requirements of configurable products are often driven by external stakeholders, such as customers, suppliers, legislation [4]. These changes and all the consequences they have, need to be incorporated across different data management systems, to ensure that the outcome of the configurator is valid and up-to-date. As the complexity of handling of configuration data increases along with the complexity of products and processes, when these changes vary across geographic location and time, the task of ensuring that all configuration data are up-to-date becomes rather challenging and time-consuming.
For instance, when engineers are designing products, they need to be aware of any changes in the legal requirements that the configurable products need to fulfill. Furthermore, sharing market requirements and customer preferences lead to avoidance of over- or underengineering products [16]. In the configuration process, this can be achieved by limiting the solution space by adding rules. This has a direct impact on reducing lead times for engineers to prepare specifications for the products along with the number of errors contained in these specifications.

Furthermore, when defining the solution space of the product offerings, manufacturers are able to identify products with low sales volumes, low profitability, and high complexity costs. When these products are eliminated, there is no need to maintain them in the IT systems anymore, engineering hours are saved and sales personnel provide better guidance to the customers. Besides, the quality of specifications sent to production is increased, though generation of valid bills-of-material (BOMs). To achieve this, a certain level of maturity in the organization is required. This includes alignment and integration of product configurators with IT systems, process and product standardization and crossorganizational collaboration [2].

In addition to these findings, control and reduction of product complexity has a direct impact in the manufacturing phase of configurable products, where components are produced and kept in stock for extended periods of time, until they become obsolete or outdated [17]. When these components are eliminated, the production process can be optimized by having more accurate planning and batch sizes, and reduction of work hours and waste $[18,19]$. As a consequence, the cycle time for the manufacturing process is reduced along with the costs, which leads to decreased delivery time and improve on time delivery [20].

A valid and up-to-date product configuration model accommodates several needs when it comes to servicing [4]. There are products with long lifecycles, e.g. aircrafts, cars, wind turbines; when times comes for maintenance the original product or some of its components are not produced anymore. As the technology advances rapidly, new products constantly replace the old ones; changes in regulations or even natural causes can be responsible for elimination of several products. As a result, maintenance becomes a challenge. Therefore, there is a need for keeping track of all the changes in a product model to be able to assess the most recent version of the configuration.

This leads to a reduction in the number of errors and the hours spent for servicing. The efficiency of the service phase is improved together with the quality. In addition, predictive maintenance becomes significantly more efficient, as the company has the possible of keeping track of all its products in the field and how they behave. This feedback is valuable for engineers re-designing products and developing new. This direction in the service phase is strongly supported by the digital twin trend. Digital twins are developed based on the products installed, which are 
being monitored, the collected data are analyzed, and predictive capabilities are advanced [21].

Implementing a PC in the service phase can assist to overcome these challenges and experience certain benefits. Yet without connecting it to the other lifecycle phases, IT systems and parts of the organization, the realized benefits are significantly less and more difficult to achieve. Hence, the impact that the benefits have on a company, is highly related to the maturity of the organization in terms of the cross-organizational collaboration, integration of IT systems and knowledge sharing among individual employees and business units.

\section{METHODOLOGY}

The focus of this research is to examine the evolution of implementing PCs across all lifecycle phases of a configurable product. Case study is selected as the research method, due to the nature of this research [22]. Since we want to examine how the use of product configurators are extended from sales to engineering, manufacturing and service phase, we need to provide empirical evidence to support the findings from the literature.

The case study includes 59 companies using product configurators in several lifecycle phases of their configurable products. The implementation of the PCs covers a specific period of time, from 2003 to the first quarter of 2018. Data collection included semi-structured interviews with managers from the case companies and documentation related to the PCs in use. The documentation included data regarding the purpose of the $\mathrm{PCs}$, the requirements and the main functionalities of the system, the teams involved in the development and maintenance of the $\mathrm{PC}$, the connection points with other IT systems for data retrieval (input and output), the user groups and what were the expected goals by the implementation of PC. Based on these data, the research team was able to analyze the use of PC in each case company, in terms of coverage of lifecycle phases.

\section{RESULTS}

\section{A. Overview the case studies}

The 59 case companies are manufacturers of configurable products, from the automotive, industrial equipment and machinery, and consumer goods sector. The companies are considered to be highly representatives of their respective business sectors. The size of the companies is medium (250-1000 employees) and large (above 1000 employees). The main commonality across the examined companies is that they have been utilizing at least one PC in one of the lifecycle phases of their configurable products. Additionally, they all operate worldwide. All case companies have production facilities across several geographic locations; they serve international markets and have a global network of suppliers.

\section{B. Findings}

The first step of the analysis includes the number of product lifecycle phases in which the case companies are utilizing a PC. Table I demonstrates the results. As it can be seen, out of the total 59 case companies that are examined, 36 companies are utilizing a PC to handle configuration data only in one lifecycle phase, while 22 companies have implemented PCs in two lifecycle phases. There is only one case company that utilizes PCs to handle product configuration data in three lifecycle phases.

TABLE I

NO. OF LIFECYCLE PHASES COVERED BY PCS

\begin{tabular}{lllll}
\hline $\begin{array}{l}\text { No. of } \\
\text { lifecycle } \\
\text { phases }\end{array}$ & 1 & 2 & 3 & 4 \\
\hline $\begin{array}{l}\text { No. of } \\
\text { case } \\
\text { companies } \\
\% \text { of case } \\
\text { companies }\end{array}$ & 36 & 22 & 1 & 0 \\
\hline
\end{tabular}

The second step of the analysis revealed which are the lifecycle phases that PCs are covering in the 59 case companies. As expected, and in alignment with the literature [8,9], the majority of the analyzed case companies have PCs in the sales phase (67\%). Engineering is the phase following with $25 \%$ of the examined companies reporting the use of PCs, however there is a significant difference between the first and the second place. For manufacturing and service, only $4 \%$ of the cases have documented PCs utilization in each of other two product lifecycle phases. Table II presents these findings.

TABLE II

NO. OF LIFECYCLE PHASES COVERED By PCS

\begin{tabular}{lllll}
\hline $\begin{array}{l}\text { Lifecycle } \\
\text { phases* }\end{array}$ & E & S & M & SE \\
\hline $\begin{array}{l}\text { No. of } \\
\text { case }\end{array}$ & 21 & 56 & 3 & 3 \\
$\begin{array}{l}\text { companies } \\
\% \text { of case } \\
\text { companies }\end{array}$ & $25 \%$ & $67 \%$ & $4 \%$ & $4 \%$ \\
\hline \multicolumn{4}{c}{$*$ E: Engineering, S: Sales, M: Manufacturing, SE: Service }
\end{tabular}

To better understand the results presented in Tables I and II, we analyze the possible combinations of lifecycle phases where PCs are used. By identifying specifically in which lifecycle phases product data are handled by PCs and what are the most common combinations, we can have a better understanding of the tendency of utilizing PCs across a product's lifecycle phases. Fig. 1 illustrates the overall results, for the 59 cases and the specific 
lifecycle phases and combinations that they utilize PCs for the period 2003-2018. As it can be seen from the chart, there are 33 case companies utilizing PCs only during the sales phase and 3 cases only during the engineering phase. The remaining 23 cases have different combinations of lifecycle phases where a PC is utilized.

Case studies 2003-2018

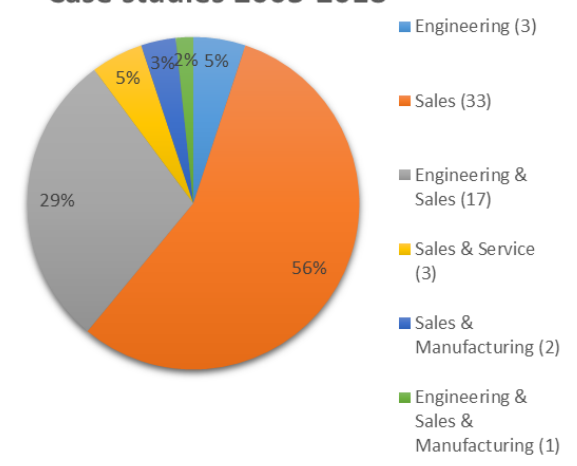

Fig. 1. Distribution of case studies based on the lifecycle phases covered by PCs.

By taking a deeper dive into the analysis, we found that there is a significant difference between number of lifecycle phases that are covered by PC and when this PC was implemented. The cases that implemented PCs in the more recent years from the period examined tend to include more than one lifecycle phases. In particular, we identified that out of the 23 cases that cover a combination of product's lifecycle phases by a PC, only one case has started the utilization during the period 2003 to 2014 . The 22 remaining cases are placed during the period 2014 to 2018. Table III shows this distribution of cases and lifecycle phases over time.

TABLE III

PROJECT DISTRIBUTION

\begin{tabular}{lcccccrr}
\hline $\begin{array}{l}\text { No. of } \\
\text { cases }\end{array}$ & Total & E & S & $\begin{array}{c}\text { E \& } \\
\text { S }\end{array}$ & $\begin{array}{c}\text { S \& } \\
\text { SE }\end{array}$ & $\begin{array}{r}\text { S \& } \\
\text { M }\end{array}$ & $\begin{array}{r}\text { E \& } \\
\text { S \& } \\
\text { M }\end{array}$ \\
\hline $2003-2014$ & 10 & 1 & 8 & 1 & 0 & 0 & 0 \\
$2015-2018$ & 49 & 2 & 25 & 16 & 3 & 2 & 1 \\
\cline { 2 - 8 } Total & 59 & 3 & 33 & 17 & 3 & 2 & 1 \\
\hline
\end{tabular}

*E: Engineering, S: Sales, M: Manufacturing, SE: Service

As it can be seen from Table III, during the period 2003-2014 the number of cases that have implemented a PC across different lifecycle phases is very limited (only one case). On the contrary, for the following period 20152018, we can see a significant increase in the number of cases that implemented PCs to handle products in more than one lifecycle phase. These results are aligned with the literature $[1,4]$.

However, there are no cases reporting PC utilization as a standalone solution during the manufacturing or the service phase of their configurable products. This can be explained due to the fact that if products are not included in a PC during the early stages of their life cycles, it is too difficult to start using a PC during manufacturing. Similarly, it can be argued that utilizing a PC only in the end of a product's life cycle, during the service phase, it will not bring the expected value, for instance in terms of cost savings or use of the feedback for re-engineering purposes.

Based on these results, it can also be concluded that the first point of extended use of PCs for configurable products is the collaboration between the engineering and sales phase. This can be explained, as these two phases are also more mature in terms of product modeling and the ones that have a more extended product data coverage by PCs, as shown in Table II.

\section{DISCUSSION}

The findings from the analysis show a tendency towards the extension of utilizing PCs for configurable products across all lifecycle phases. The results verify the identified need of extending the use of PCs to enhance a cross-organizational collaboration, moving away from the current silo structures [2,4]. CLM serves this need by providing a universal product model, which includes product information that describes the configuration relevant features and rules across all lifecycle phases.

Change management of configuration data and process standardization are some of the underlying principles driving this need for CLM solutions. In addition, the increasing product complexity and the demand of customized solutions from customers are areas whose impact can be controlled by implementing such solutions to handle in a more effective and efficient manner the product portfolio.

An aspect that cannot be seen from this analysis is the extension of a configuration project within a business unit or across different business units. There are examples from these 59 projects where the case company has expanded the range of products to be included in the configurator or the number of departments (with different geographical location) that are using the PC. However, due to lack of data verification this part is not included in the current analysis. This should be further examined, as the size and the complexity of the configurator might have an impact on the expected benefits [23].

\section{CONCLUSION}

The focus of this research article is to identify and analyze the current trends on the utilization of PCs from an industrial point of view. The article discusses how the utilization of PCs is extended to include product knowledge that covers the entire lifecycle of a configurable product. Case studies have been conducted to investigate this phenomenon. Based on the results from 
the 59 case studies, the sales configurator remains the most popular solution for manufacturers of configurable products, aiming at reducing cost and lead times while improving the quality of their configurable products. The empirical evidence also shows that there is an increasing number of manufacturers extending the use of PCs to more lifecycle phases, such as engineering, manufacturing and services.

The literature review also supports these findings from the empirical evidence. There is a significant amount of research papers focusing on sales configurators, while there is limited focus on the other lifecycle phases of the configurable products. This research aims at contributing to this gap by providing an overview of the current trend in the industry.

Based on the results of this research, there are several areas identified that require further study. The scoping of a CLM solution, the integrations to other IT systems, the organizational structure and knowledge sharing are research areas that would support to overcome the challenges of implementing CLM solutions and improve the realized benefits.

In conclusion, the need for CLM solutions is supported by the results of the analysis from the 59 case studies, indicating that there is a strong tendency in extending the use of PCs across all lifecycle phases of configurable products. This tendency is expected to increase given the fact that the digitalization era that we are currently experiencing requires agile organizations adaptive to changes and supports seamless integration across not only products' lifecycle phases but also business units and entire organizations.

\section{REFERENCES}

[1] R.M. Rangan, S.M. Rohde, R. Peak, B. Chadha, P. Bliznakov, Streamlining Product Lifecycle Processes: A Survey of Product Lifecycle Management Implementations, Directions, and Challenges, J. Comput. Inf. Sci. Eng. 5 (2005) 227. doi:10.1115/1.2031270.

[2] R. Batenburg, R.W. Helms, J. Versendaal, PLM roadmap: stepwise PLM implementation based on the concepts of maturity and alignment, Int. J. Prod. Lifecycle Manag. 1 (2006) 333. doi:10.1504/IJPLM.2006.011053.

[3] H. Bruun, N. Mortensen, U. Harlou, M. Wörösch, PLM system support for modular product development, Comput. Ind. 67 (2015) 97-111.

[4] J. Tiihonen, T. Soininen, T. Männistö, R. Sulonen, State-ofthe-practice in product configuration - a survey of 10 cases in the Finnish industry, Knowl. Intensive CAD. (1996) 95114. doi:10.1.1.55.1960.

[5] Configit A/S, CLM DECLARATION, (2015) 1-2. https://configit.com/configit_wordpress/wpcontent/uploads/2015/10/CLM-Declaration-2015.pdf (accessed January 8, 2018).

[6] M.M. Andreasen, 45 Years with design methodology, J. Eng. Des. 22 (2011) 293-332. doi: $10.1080 / 09544828.2010 .538040$.
[7] L.L. Zhang, E. Vareilles, M. Aldanondo, Generic bill of functions, materials, and operations for SAP2 configuration, Int. J. Prod. Res. 51 (2013) 465-478. doi:10.1080/00207543.2011.652745.

[8] A. Myrodia, K. Kristjansdottir, L. Hvam, Impact of product configuration systems on product profitability and costing $\begin{array}{llll}\text { accuracy, } & \text { Comput. } & \text { Ind. } & 88\end{array}$ doi:10.1016/j.compind.2017.03.001.

[9] C. Forza, F. Salvador, Product information management for mass customization, Palgrave Macmillan, New York, 2007.

[10] V.E. Barker, D.E. O'Connor, J. Bachant, E. Soloway, Expert systems for configuration at Digital: XCON and beyond, Commun. ACM. 32 (1989) 298-318. doi:10.1145/62065.62067.

[11] A. Felfernig, G.E. Friedrich, D. Jannach, UML as domain specific language for the construction of knowledge-based configuration systems, Int. J. Softw. Eng. Knowl. Eng. 10 (2000) 449-469.

[12] H. Elmaraghy, A. Azab, G. Schuh, C. Pulz, Managing variations in products, processes and manufacturing systems, CIRP Ann. - Manuf. Technol. 58 (2009) 441-446. doi:10.1016/j.cirp.2009.04.001.

[13] M. V Martin, K. Ishii, Design for variety: developing standardized and modularized product platform architectures, Res. Eng. Des. 13 (2002) 213-235. doi:10.1007/s00163-002-0020-2.

[14] M.. Tseng, R.J. Jiao, Design for Mass Customization, CIRP Ann. Manuf. Technol. 45 (1996) 153-156. doi:10.1016/S0007-8506(07)63036-4.

[15] L. Hvam, A. Haug, N.H. Mortensen, C. Thuesen, Observed benefits from product configuration systems, Int. J. Ind Eng. Appl. Pract. 20 (2013) 329-338.

[16] G. Hong, L. Hu, D. Xue, Y.L. Tu, Y.L. Xiong, Identification of the optimal product configuration and parameters based on individual customer requirements on performance and costs in one-of-a-kind production, Int. J. Prod. Res. $46 \quad$ (2008) 3297-3326. doi:10.1080/00207540601099274.

[17] A. Myrodia, M. Bonev, L. Hvam, Two-way substitution effects on inventory in configure-to-order production systems, in: 2015 IEEE Int. Conf. Ind. Eng. Eng. Manag., IEEE, Singapore, Singapore, 2015: pp. 1-5 doi:10.1109/IEEM.2015.7850285.

[18] H. Xu, D.D. Yao, S. Zheng, Optimal control of replenishment and substitution in an inventory system with nonstationary batch demand, Prod. Oper. Manag. 20 (2011) 727-736. doi:10.1111/j.1937-5956.2010.01191.x.

[19] F.K. Pil, M. Holweg, Linking Product Variety to OrderFulfillment Strategies, Interfaces (Providence). 34 (2004) 394-403. doi:10.1287/inte.1040.0092.

[20] A. Myrodia, K. Kristjansdottir, S. Shafiee, L. Hvam, Product configuration system and its impact on product's life cycle complexity, in: IEEE Int. Conf. Ind. Eng. Eng. Manag., 2016. doi:10.1109/IEEM.2016.7797960.

[21] D. Hartmann, M. Herz, U. Wever, Model Order Reduction a Key Technology for Digital Twins, in: W. Keiper, A Milde, S. Volkwein (Eds.), Educed-Order Model. Simul. Optim., Springer, 2018. doi:10.1007/978-3-319-75319-5_8.

[22] C. Voss, N. Tsikriktsis, M. Frohlich, Case research in operations management, Int. J. Oper. Prod. Manag. 22 (2002) 195-219. doi:10.1108/01443570210414329.

[23] K. Kristjansdottir, S. Shafiee, L. Hvam, M. Bonev, A. Myrodia, Return on investment from the use of product configuration systems - A case study, Comput. Ind. 100 (2018) 57-69. doi:10.1016/j.compind.2018.04.003. 